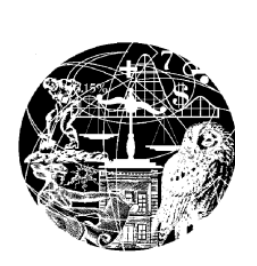

\title{
Impactos ambientais E ECONÔMICOS DOS VEÍCULOS ELÉTRICOS E HÍBRIDOS PLUG-IN: UMA REVISÃO DA LITERATURA
}

DOI: $10.12957 /$ synthesis.2015.30472

Christian Vonbun*

Resumo: Este artigo apresenta uma breve revisão da literatura acerca dos custos e benefícios de veículos elétricos e veículos híbridos do tipo plug-in (PHEV), com ênfase em seus benefícios em termos de redução da emissão de gases de estufa e gases nocivos à saúde humana. Conclui-se que os veículos híbridos, ainda que tenham de superar barreiras tecnológicas e culturais, apresentam um grande potencial de elevar não apenas a eficiência energética do setor de transporte, mas também contribuir para aumentar a eficiência e reduzir os custos relacionados à produção de energia elétrica. Esses veículos podem servir de ponte entre os veículos convencionais e os elétricos, quando o desenvolvimento tecnológico, notadamente relativo ao custo e eficiência das baterias, permitir a adoção generalizada de veículos elétricos. Todavia, é importante notar que o aproveitamento pleno do potencial de economia e de redução de emissão de poluentes está condicionado à implantação das chamadas smart grids e, mais importante, de como se configura a produção marginal de energia elétrica na região e no período considerados.

Palavras-chave: Veículos Elétricos; Efeito Estufa; Emissões; Avaliação Econômica; Economia Ambiental.

Economic and environmental impacts of electric and eletro-hybrid vehicles: a brief literature review

Abstract: This paper presents a brief literature review concerning the costs and benefits of electric vehicles and hybrid electric vehicles, highlighting their advantages in terms of greenhouse gas emissions reductions. Even though electric and electro-hybrid vehicles must still overcome many cultural and technological barriers, they present a great potential in improving the energy efficiency of the transportation system, as well as reducing the costs of electric energy production and transmission. The hybrid vehicles may close the technological and operational gap between the old internal combustion powered vehicles and the new electric cars, until new improvements on batteries allow the widespread introduction of electric cars as the standard individual transportation vehicles. Nevertheless, it is imperative to stress that the full potential benefits of these vehicles is conditioned to the implementation of Smart Grids that enable the electric system to use them as a reservoire of energy that provides back up power to the system, to be employed in peak consumption hours. It is also vital to ensure that the required incremental energy production is proportionately cleaner than the internal combustion vehicles they replace.

Keywords: Electric Vehicles; Greenhouse Effect; Emissions; Economic Evaluation.

Classificação JEL: Q43, Q47, Q48, Q50, Q51, Q52, Q53, Q54, Q55, Q56, Q58. 
*Mestre em Economia, Técnico do Instituto de Pesquisa Econômica Aplicada - IPEA e professor da Universidade Cândido Mendes - UCAM.

\section{INTRODUÇÃO}

A atividade humana está alterando a composição da atmosfera em ritmo acelerado. De acordo com o Intergovernmental Panel on Climate Change (IPCC, 2013), a concentração de $\mathrm{CO}_{2}$ passou de 276,7 PPM em 1775 - antes da Revolução Industrial - para 390,5 PPM, em 2011, por exemplo. ${ }^{1}$ Esse e outros gases possuem a característica de reter calor, elevando a temperatura global, podendo causar efeitos catastróficos sobre os ecossistemas, as populações humanas e inclusive à atividade econômica global.

De acordo com Perujo, Thiel e Nemry (2011), em 2006, 31\% da energia consumida foram para o setor de transportes - com $82 \%$ destinados ao transporte rodoviário -, responsável por $25 \%$ das emissões de $\mathrm{CO}_{2}$. Em 2007, este tipo de transporte foi responsável por $71 \%$ das emissões de $\mathrm{CO}_{2}$, enquanto carros de passageiros emitiram 63\%. De acordo com Managi (2012), a International Energy Agency (IEA) indicou que o setor de transporte respondeu, em 2007, por 17\% das emissões de $\mathrm{CO}_{2}$ relacionadas à energia, prevendo elevação desse valor para 2009.

De acordo com o Ministério da Ciência, Tecnologia e Inovação (MCTI), o Brasil emitiu 1.246.477 Gg de $\mathrm{CO}_{2}$ em 2010. Cerca de 32\% dessas emissões foram atribuídas ao setor de energia, com o setor de transporte representando 41,9\%, e o transporte rodoviário 38,5\% (Brasil, 2013).

A Conferência das Nações Unidas para o Meio-Ambiente e o Desenvolvimento (Rio-92) adotou a Convenção-Quadro das Nações Unidas sobre Mudança do Clima (UNFCCC), assinada por 192 países, que objetiva criar regras para limitar o aquecimento global, por meio de diversas políticas que incluem metas de emissões de gases de estufa. Em seguida, em 1997, foi assinado por 37 países o Protocolo de Kyoto, que buscava reduzir as emissões dos signatários em 5,2\% em relação a 1990, ainda que houvessem metas diferenciadas por países. Em 2009, foi assinado o Acordo de Copenhague, que estabelece metas nacionais de emissões, que pretendem ser suficientes para limitar o aquecimento global a um aumento de temperatura máximo de $2^{\circ} \mathrm{C}^{2}$

A Tabela 1 mostra as porcentagens de redução de emissões constantes no Acordo de Copenhague para alguns países selecionados.

Alcançar essas metas, naturalmente, passa pela alteração da matriz energética, o que envolve a incorporação de novas tecnologias em diversos setores da atividade humana.

Tabela1 - Metas do Acordo de Copenhague - países selecionados

\begin{tabular}{|l|l|l|}
\hline País & $\begin{array}{l}\text { Meta de redução das emissões para } \\
2020^{1} \\
(\%)\end{array}$ & Ano-base \\
\hline Austrália & $5-15$ & 2000 \\
\hline Canadá & 17 & 2005 \\
\hline Comunidade Europeia & $20-30$ & 1990 \\
\hline Japão & 25 & 1990 \\
\hline Noruega & $30-40$ & 1990 \\
\hline Estados Unidos & 17 & 2005 \\
\hline Rússia & $15-25$ & 1990 \\
\hline Coreia do Sul & 30 & Tendência projetada para 2020 \\
\hline México & 30 & Tendência projetada para 2020 \\
\hline África do Sul & 34 & Tendência projetada para 2020 \\
\hline Indonésia & 26 & Tendência projetada para 2020 \\
\hline Brasil & $36,1-38,9$ & Tendência projetada para 2020 \\
\hline China & $40-45$ & $\begin{array}{l}\text { Tendência da intensidade de } \mathrm{CO}_{2} \\
\text { no PIB projetada para 2020 }\end{array}$ \\
\hline Índia & $\begin{array}{l}\text { Tendência da intensidade de } \mathrm{CO}_{2} \\
\text { no PIB projetada para 2020 }\end{array}$ \\
\hline
\end{tabular}


Fonte: Motta, Hargrave e Luedemann (2011).

Nota: ${ }^{1}$ Em relação ao ano-base.

Apesar disso, a predominância do setor de transportes o leva ao centro das atenções. Como o setor que mais emite, potencialmente é o que mais apresenta possibilidades de redução de emissões. Assim, do ponto de vista global, uma possível solução, ou, mais realisticamente, uma possível forma de mitigação de parte das emissões seria a substituição dos veículos por outros não poluentes.

Existem diversas tecnologias possíveis de veículos que produzam nenhuma ou pouca emissão de gases de estufa. Entre eles os carros elétricos, os veículos a célula de hidrogênio e os veículos de combustão de hidrogênio - cujo subproduto não inclui $\mathrm{CO}_{2}$. Entretanto, tanto a eficiência energética e térmica quanto a viabilidade econômica dos veículos elétricos domina os demais. Isto não implica, contudo, que a substituição dos atuais veículos movidos a combustíveis fósseis seja simples. Diversos fatores devem ser considerados, como: custo dos veículos; disponibilidade de energia elétrica e os níveis de emissões requeridos para gerá-la; relações entre os aspectos técnico-operacionais desses veículos e as preferências dos consumidores, aspectos relativos à segurança desses veículos e outros aspectos econômicos.

Os veículos elétricos se dividem entre os veículos elétricos (EV), propulsados somente por motores elétricos, cuja energia é armazenada em baterias - e oriunda da rede de abastecimento de energia elétrica - e os híbridos, que combinam motores elétricos com motores a combustão interna. Os híbridos (HEV), por sua vez, podem ter motores a combustão destinados apenas a carregar as baterias ou a ser corresponsáveis pela tração dos veículos, dividindo a tarefa de propeli-los com os motores elétricos sendo, ao mesmo tempo, responsáveis por carregar as baterias. Finalmente, os híbridos do tipo plug-in (PHEVs) são os que, além de possuírem motores a combustão, também podem ser ligados à rede elétrica para a recarga de suas baterias, podendo assim prescindir, dependendo do uso, do acionamento do motor a combustão, pelo menos em pequenos trajetos.

Assim, faz-se necessária uma revisão da literatura sobre o tema, que busca consolidar o conhecimento que se tem sobre o assunto.

Mais que isso, é importante considerar se os benefícios desses veículos valem a pena, quando considerados os custos da adoção da tecnologia, que vão desde a geração de energia e suas emissões à adaptação dela aos hábitos dos consumidores e os aspectos relacionados à segurança.

\section{REVISÃO DA LITERATURA}

\subsection{LITERATURA NÃO ACADÊMICA}

Alguns elementos importantes para a avaliação dos veículos elétricos ainda não foram muito elaborados pela literatura, especialmente no que diz respeito à segurança das baterias. Nem todos os eventos recentes de incêndios em baterias de veículos elétricos foram totalmente explicados e remediados, como casos de incêndios em veículos Chevrolet, Fisker e Mitsubishi (Bond Jr., 2012; Jensen, 2012; Green et al., 2012; Cooper e Matsuda, 2013).

Também há pouco sobre o resultado dos estímulos econômicos dados pelo governo norteamericano a fabricantes de veículos e de baterias, visto que muitas empresas agraciadas com subsídios, empréstimos e isenções pediram falência ou concordata recentemente, como é o caso da Fisker - fabricante de carros elétricos; da Coda - fabricante de carros elétricos; A123 Systems fabricante de baterias; Aptera - fabricante de carros elétricos, entre outros.

Do mesmo modo ainda não repercutiu na literatura a desaceleração do crescimento das vendas dos veículos movidos a combustíveis alternativos, inclusive em função da queda nas vendas de elétricos e híbridos nos Estados Unidos, mesmo havendo casos de sucesso, como o Toyota Prius e os veículos da fabricante de elétricos Tesla.

Falta também, na literatura, a comparação de híbridos com veículos a diesel que, ainda que emitam alguns poluentes em maior quantidade que os movidos a gasolina - como $\mathrm{NO}_{\mathrm{x}}$ e particulados produzem menos $\mathrm{CO}_{2}$, sendo muito mais eficientes em termos de consumo de combustível. Assim, falta uma comparação mais ampla entre veículos híbridos a gasolina e veículos a diesel. Ainda se 
aguarda, contudo, a introdução de veículos híbridos diesel-elétricos, que provavelmente serão ainda mais eficientes que os supramencionados.

Uma comparação anedótica, mas ainda assim interessante, da conceituada revista Car and Driver que é viesada em prol do prazer ao dirigir e das características esportivas dos veículos - confrontou quatro versões do mesmo carro (Swan, 2013), o Volkswagen Jetta. São comparadas as versões diesel, híbrida (HEV - hybrid electric vehicle, ${ }^{3}$ ou veículo híbrido elétrico) e duas a gasolina - uma mais econômica, outra mais luxuosa e de melhor desempenho. O comparativo considerou custo de aquisição, manutenção, economia de combustível e avaliações subjetivas de prazer ao dirigir e "consciência ecológica". Os modelos custavam entre US\$23.690 - versão a gasolina mais barata, com motor cinco cilindros de 2,5 litros - e US\$ 30.120 - versão HEV com motor 1,4L turbo. Os outros dois modelos são dois de quatro cilindros turbo de dois litros, um a diesel, outro a gasolina. $\mathrm{O}$ modelo a diesel foi o mais econômico, apresentando rendimento de 39 milhas por galão de gasolina $(16,58 \mathrm{~km} / \mathrm{l})$, seguido de perto pelo híbrido $(16,16 \mathrm{~km} / \mathrm{l})$. Os modelos a gasolina gastaram $13,18 \mathrm{~km} / \mathrm{l}$ e $11,05 \mathrm{~km} / \mathrm{l}$, para o 2.0 e o 2.5 , respectivamente. Em tese, contudo, o híbrido é o mais econômico, pois está certificado na Agência de Proteção Ambiental norte-americana (EPA - Environmental Protection Agency) por fazer 42 MPG na cidade e 48 na cidade (17,85 e 20,4 km/l, respectivamente), contra 30 e 42 do diesel (12,75 e 17,85 km/l, respectivamente), corroborando o que a literatura ressalta: o consumo dos híbridos depende sobremaneira da maneira como se dirige. Quanto ao desempenho, o melhor foi o 2.0 a gasolina (turbo), seguido do híbrido e do diesel. Como resultado do comparativo, não supreendentemente, a Car and Driver colocou o modelo esportivo em primeiro (2.0 turbo a gasolina), mas, também surpreendentemente teve o híbrido em segundo, pois apresentou bom desempenho e bom consumo de gasolina, em parte propiciado pela vantagem de poder ter um motor menor, suplementado pelo motor elétrico. A contrapartida foi o seu maior peso - devido às baterias o que piorou a economia, o desempenho e a dirigibilidade. O segundo lugar para um híbrido nesta revista revela um pouco de seu potencial. Mas é importante notar a melhor economia do diesel em relação ao HEV - ainda que, provavelmente, se se tratasse de um PHEV a economia seria superior. ${ }^{4}$

Desse comparativo decorrem alguns resultados interessantes: os híbridos parecem ser capazes de reduzir as emissões e satisfazer os consumidores mais exigentes, a despeito de seu acréscimo de preços. Logo, a tecnologia atual parece ser capaz de derrubar algumas das barreiras tecnológicas que afetavam negativamente a aceitação desses veículos. Todavia, do ponto de vista das emissões, seu modo de uso pode limitar os efeitos práticos da tecnologia, visto que os modelos a diesel acabaram por emitir menos gases que produzem efeito estufa (GHG - greenhouse gases) sob condições severas de uso - impostas durante o teste da revista -, o que revela ser também necessária a avaliação do diesel como alternativa menos custosa para se reduzir os GHGs.

Ainda assim, há diversos estudos acerca dos efeitos líquidos da adoção de veículos elétricos e híbridos, sua comparação com tecnologias alternativas, seus impactos sobre emissões e sobre as redes de energia elétrica.

\subsection{LITERATURA ACADÊMICA}

Quanto à literatura acadêmica, uma boa revisão dos conceitos pode ser obtida em Romm e Frank (2006), que fazem uma apresentação dos veículos híbridos do tipo plug-in, ressaltando suas vantagens. Reconhecem o aumento de preços dos PHEVs em relação aos veículos convencionais, em função das baterias e dos mecanismos de controle, além do decorrente acréscimo de peso, que freia o acréscimo de eficiência energética. Em função do aumento de preço, o payback do investimento em um veículo elétrico - em comparação com um convencional - pode demorar alguns anos. Mencionam os ganhos de eficiência da frenagem regenerativa de energia (regenerative braking), que recupera a energia cinética das frenagens, recarregando as baterias. Adicionalmente, lembram que os motores elétricos, ao adicionarem potência aos motores a combustão, permitem que esses sejam menores e mais eficientes em termos energéticos, pois podem fornecer potência adicional quando necessário. Os autores também ressaltam algumas tecnologias até então associadas aos híbridos, que os tornam mais eficientes que os veículos convencionais, como a direção assistida eletricamente e o ar condicionado alimentado pelas baterias, além do sistema start stop - que desliga o motor a combustão quando o carro fica parado. ${ }^{5}$ Os autores mencionam os ganhos em termos de economia com os híbridos, mas comentam a necessidade de elevar a longevidade das baterias. Um dos mais importantes pontos do 
artigo é a exposição da superioridade dos veículos PHEV em relação aos veículos a célula de hidrogênio, em especial no que diz respeito à eficiência energética e dificuldades na distribuição de hidrogênio.

A literatura acerca dos veículos elétricos pode ser dividida em três grandes grupos. A primeira trata de análises acerca da aceitação dos veículos híbridos/elétricos do ponto de vista do consumidor. Esse grupo de artigos pressupõe que a solução de longo prazo para os problemas ambientais e de finitude dos recursos naturais requer veículos elétricos - os híbridos tenderiam a ser um passo intermediário de ligação entre a nova e a velha tecnologia -, logo, faz uma análise do ponto de vista do consumidor, ou da viabilidade financeira de adquirir tais veículos ou sobre estimativas da demanda por esses veículos, em função de preços, subsídios e da substituição dos veículos convencionais pelos elétricos. O segundo grupo se preocupa fundamentalmente com os custos e benefícios sociais desses veículos, considerando os impactos dos mesmos sobre a rede de produção e distribuição de eletricidade e sua capacidade de alimentar os veículos elétricos e híbridos, o que também pressupõe que se considere a transição tecnológica dos veículos convencionais, para os híbridos, ou necessária ou inevitável. Esse grupo destaca um dos aspectos mais interessantes da adoção da tecnologia de carros elétricos: a possibilidade de gerar fortes externalidades positivas sobre a rede de distribuição de energia, por intermédio do que se convencionou chamar de smart grids. Trata-se de um setup simbiótico entre os carros elétricos e o sistema de geração e distribuição de energia elétrica, de modo que os carros elétricos são carregados pela energia do sistema, mas um comando central que se comunica com os veículos pode usar a energia das baterias para atender a demandas de energia nos horários de pico, economizando quantias consideráveis na expansão da capacidade do sistema para atender aos referidos horários. As smart grids podem ajudar decisivamente na viabilização do carro elétrico, o que, por si só, justifica a segmentação aqui proposta. Finalmente, o terceiro grupo de fato busca avaliar se os custos compensam os benefícios da transição para híbridos e/ou elétricos. Isto é feito tanto em termos das emissões líquidas quanto da avaliação financeira das externalidades face aos benefícios de sua adoção, por meio da redução dessas externalidades e, por vezes, também de seu efeito benéfico sobre a rede de geração e distribuição de energia elétrica.

Algumas conclusões que advêm dos estudos estão descritas a seguir.

1) A tecnologia do setor de geração e distribuição de eletricidade influi decisivamente na avaliação de custos e benefícios dos veículos. Isso inclui quão poluente é a geração marginal de energia. Países ou localidades com as matrizes mais limpas tendem a avaliar de forma mais positiva os veículos elétricos e as com matrizes mais sujas, menos.

2) Novas tecnologias, notadamente as smart grids, podem mitigar boa parte dos custos de adoção da tecnologia de carros elétricos.

3) Podem ocorrer trade-offs entre emissões de gases de estufa e gases tóxicos nocivos à saúde, especialmente se a tecnologia de geração de energia for suja.

4) Ainda há barreiras tecnológicas a vencer até que o veículo elétrico seja visto como substituto perfeito para os convencionais - incluindo o custo, a durabilidade e a autonomia das baterias -, bem como há uma diferença de custo que pode ser substancial. Esses custos nem sempre se justificam do ponto de vista social. Dependendo da metodologia e do escopo geográfico - logo, também da tecnologia de geração e transmissão de eletricidade - dos estudos, nem sempre esses justificam a subvenção estatal a esses veículos. Sem subvenções, enquanto os consumidores não virem esses veículos como substitutos perfeitos ou melhores do que os veículos convencionais, haverá dificuldades para a implementação da tecnologia.

$\mathrm{Na}$ próxima seção, constam artigos com análises financeiras que consideram os benefícios privados da aquisição de veículos elétricos e/ou híbridos, frente aos convencionais. Na seção 4, são resumidos artigos que fazem análises sociais, notadamente quanto a aspectos da absorção de EVs e PHEVs pelas redes de produção e distribuição de energia, especialmente sob a hipótese de adoção de smart grids, e sua emissão líquida de poluentes - de estufa ou não. Na seção 5, apresentam-se as conclusões. 


\section{ANÁLISES SOB A ÓTICA DO CONSUMIDOR}

\subsection{ESTIMAÇÃO DA DEMANDA}

Há uma linha de pesquisa que estima a demanda prospectiva pelos veículos elétricos e/ou híbridos. O que motiva este tipo de pesquisa é a importância de ter em mente que apenas na presença de benefícios claros os consumidores irão migrar para a nova tecnologia, o que ressalta o desafio técnico de obter tecnologias que tragam os referidos benefícios financeiros ao consumidor.

Zito e Silva (2004) estimam a demanda potencial dos consumidores italianos por veículos elétricos, dados preços e subsídios e custos operacionais, também em função de fatores explicativos das famílias, como distância percorrida, número de veículos da família, existência de garagens e outros. Eles usaram preferências reveladas por meio de questionários e uma estimativa logit. Concluem que o maior limitativo à demanda dos EVs é o elevado preço dos veículos. O elevado custo das baterias também aumenta seu custo de manutenção - em função também de sua durabilidade limitada.

Não obstante, as limitações dos carros elétricos podem ser "solucionadas" no caso de famílias com mais de um veículo: um elétrico para a mobilidade urbana diária, um de combustão interna para viagens e longos trajetos. Os autores ressaltam que os veículos elétricos têm características que os tornam mais adequados ao uso urbano diário, com trajetos curtos. Logo, os carros elétricos podem ser uma solução viável em alguns cenários, incluindo frotas comerciais e o compartilhamento de automóveis. Todavia, o alto preço e os "baixos incentivos" percebidos na Itália inviabilizam uma estimativa para o market share dos EVs. Ainda assim, foi identificada uma disposição a pagar das pessoas pelos carros elétricos e seus benefícios ambientais, fator fundamental para sua penetração no mercado, junto com o nível de subsídios, regulações etc.

Baran (2012) faz uma boa resenha da literatura acerca de veículos elétricos e estima a demanda por veículos híbridos plug-in para o Brasil, com base em modelos de difusão tecnológica (modelo de Bass) de saturação da frota (DGS), usando também dados acerca da idade da frota e estimativas de sua expansão. De acordo com cenários acerca do consumo energético dos PHEVs, seus resultados estimam que, em 2031, a proporção da frota brasileira de veículos híbridos estará entre 13,6\% e $37,4 \%$. O consumo de gasolina estimado estaria entre $59 \%$ e $86 \%$ do que seria observado no cenário business as usual, em que os veículos convencionais continuariam a dominar o mercado, com a frota crescendo a taxas determinadas pelo modelo. No cenário mais extremo de aceitação desse tipo de veículos, prevê-se até uma queda do volume de consumo de combustíveis líquidos, incluindo o total entre derivados do petróleo e etanol. O acréscimo do consumo de energia elétrica estaria entre 14,0\% e $42,1 \%$, dependendo do cenário. O consumo energético total apresentaria uma queda entre 9,2\% e $27,5 \%$, em relação ao cenário business as usual. As principais conclusões são que o etanol seria complementar, não concorrente à gasolina; que a disposição do consumidor brasileiro em adotar novas tecnologias - sugerida pelo sucesso do pró-álcool - facilitará a difusão dos híbridos. Como sugestão de trabalhos adicionais, destacam-se a avaliação econômico-financeira dos PHEVs após a adoção de smart grids no país e a modelagem do impacto desses veículos sobre os sistemas de produção e distribuição de energia elétrica.

\subsection{ANÁLISES FINANCEIRAS}

As análises financeiras são focadas na viabilidade, do ponto de vista do consumidor, de adquirir veículos elétricos ou híbridos, vislumbrando a economia de combustível ou de gastos totais por distância percorrida. Na maioria dos casos, tais análises consideram os subsídios e incentivos do governo, logo, podem ou não incluir avaliações de custos e benefícios sociais.

Romm (2006), após concluir que 97\% do combustível utilizado por carros, vans, veículos utilitários esportivos (SUVs - sport-utility vehicles), caminhões e aviões ainda se baseiam em petróleo e que a tendência - sem intervenção do governo - da utilização desses combustíveis é francamente crescente, nota que há problemas relativos aos veículos de combustíveis alternativos (AFVs - alternative fuel vehicles). Além do ponto óbvio de se questionar se os AFVs consistem realmente em alternativas custo-eficientes de redução de emissões, algumas barreiras ao seu sucesso são citadas pelo autor: $i$ ) alto custo dos veículos; ii) problemas com a armazenagem de energia problemas de autonomia; iii) preocupações com confiabilidade e segurança; iv) elevado custo do 
combustível - se comparado à gasolina; v) estações de abastecimento limitadas; e vi) melhorias de eficiência nos carros a gasolina.

Como essas barreiras são enfrentadas, em maior ou menor grau, por todos os AFVs, elas balizaram a discussão acerca dos principais potenciais combustíveis do futuro. Romm (2006) nota que alguns combustíveis alternativos, como o etanol E-85, não vingaram em função dos problemas com a pouca disponibilidade de estações de abastecimento, por exemplo. Além disso, o gás natural sofreu com problemas de custo.

O custo também é um dos problemas listados no que concerne aos carros movidos a célula de hidrogênio. Os carros seriam caros demais, assim como a implantação de uma rede de distribuição de hidrogênio, até porque sua produção, para ser livre de emissões de carbono, é ainda mais inviável economicamente. Romm (2006) cita estudos mostrando que, considerando as emissões desde a produção do combustível até o seu uso (well-to-wheel), geraria custos até cem vezes maiores que os de veículos de combustão interna (Wald, 2004 apud Romm, 2006, p. 2611).

Todavia, no que se refere a veículos híbridos, eles são entendidos pelos autores como capazes de derrubar a maior parte das barreiras supracitadas. Os híbridos não teriam um custo tão mais elevado, e o mesmo poderia ser resolvido por meio de três fatores: $i$ ) a economia de combustível que os veículos gerariam, em função do uso de eletricidade - considerando que os híbridos sejam do tipo plug-in - e das tecnologias de recuperação de energia cinética; ii) a venda de energia armazenada às empresas de eletricidade nos momentos de consumo de pico, reduzindo o custo fixo das geradoras de energia e podendo produzir receitas não desprezíveis aos donos deste tipo de veículo - assumindo-se o uso de smart grid $;{ }^{6}$ e iii) os subsídios do governo a este tipo de veículo. Além disso, os híbridos evitariam os custos de implementação de grandes redes alternativas de abastecimento, visto que podem funcionar com gasolina normal, além de serem carregados nas próprias residências de seus proprietários.

Os híbridos também não teriam problemas de segurança substancialmente piores que os dos veículos convencionais disponíveis. Adicionalmente, o problema quanto à autonomia limitada também seria resolvido, pois no caso de a bateria acabar, os híbridos podem continuar a viagem por meio do uso e do reabastecimento de gasolina. Finalmente, o custo do combustível é menor ou igual ao da gasolina, visto que são carros com duas fontes de energia e uma delas teria aproximadamente o mesmo custo da frota convencional, mas a eletricidade é bem mais barata que a gasolina. Finalmente, os híbridos podem se beneficiar das melhorias técnicas dos carros a gasolina, visto que possuem motor de combustão interna.

Finalmente, Romm (2006) destaca as principais vantagens dos híbridos: reduzir a emissão de $\mathrm{CO}_{2}$; funcionar em curtos trajetos como veículos de emissão zero - logo, livrando de gases tóxicos centros congestionados e já poluídos por gases. Outra conclusão interessante é que mesmo em termos de emissões, os híbridos seriam quatro vezes mais eficientes que os carros de célula de hidrogênio. A substituição de metade da frota norte-americana por veículos a hidrogênio envolveria a necessidade de elevação da produção de eletricidade limpa em $1400 \mathrm{GW}$, sem contar a necessidade de substituição de combustíveis fósseis na própria geração de energia.

Simpson (2006) apresenta uma análise de custo e benefício dos veículos híbridos do tipo plug-in versus os híbridos convencionais (HEV) e os veículos a combustão não híbridos, usando o custo total de propriedade dos veículos ao longo de sua vida útil em dois cenários. Os referidos cenários são os de curto e os de longo prazo, sobre os quais se faz uma análise do custo de energia e de combustível consumidos por esses veículos. No cenário de curto prazo, suas estimativas indicam que os HEVs somente terão custo menor que os veículos convencionais após dez anos de uso. Os PHEVs nunca atingirão os custos menores dos veículos convencionais. No caso do cenário de longo prazo, os HEVs atingem custos menores que os veículos convencionais após quatro anos de uso, enquanto os PHEVs terão custos menores que os HEVs em doze anos. Ele conclui que a equação de custo-benefício dos PHEVs depende fortemente da autonomia dos veículos. Além disso, custos de combustíveis e das baterias têm, assim como desempenho e hábitos dos motoristas, uma forte influência sobre o valor que os consumidores estão dispostos a pagar pelos PHEVs. Em função da alta variabilidade das características dos PHEV então disponíveis, o autor julgou difícil prever o potencial de vendas dos PHEVs. Mas seu potencial de redução de consumo de petróleo por veículo seria muito alto, chegando a $45 \%$, melhor que os $30 \%$ dos HEVs. Todavia, ele nota que aumentos na autonomia dos PHEVs vão levar a uma elevação considerável em seus custos, e a incerteza sobre tais custos impossibilitaria o cálculo da viabilidade econômica dos PHEVs.

[SYN]THESIS, Rio de Janeiro, vol.8, n ${ }^{\circ}$ 2, 2015, p.45-63 
Sovacool e Hirsch (2009) notam que há barreiras que funcionam como obstáculos contra a popularização dos PHEVs, nos Estados Unidos. Ainda que reconheçam a existência de barreiras técnicas, como o alto custo das baterias e sua limitação de autonomia, os autores focam nas chamadas barreiras socioculturais. A primeira destas barreiras se trata do fato, relatado por Greene et al. (2007), de que os consumidores não calculam, ao avaliar a compra de um PHEV, o valor presente líquido das economias de combustível ao longo da vida dos veículos. Da mesma forma, indicam que os consumidores usam taxas de desconto elevadas e exigem um período de payback de apenas cinco meses, enquanto especialistas indicam que o payback de um PHEV pode demorar de sete a quinze anos para ocorrer, ainda que os norte-americanos troquem de carro, em média, a cada seis anos. Aparentemente, a maior parte das pessoas se demonstrou incapaz de fazer os cálculos necessários para uma avaliação econômica adequada dos PHEVs, reagindo de forma pouco racional - e duradoura - a variações nos preços da gasolina. Isso, segundo os autores, sugere um problema de bounded rationality. Outro problema é o preço inicial mais elevado dos PHEVs. Outros fatores sociológicos são a associação de veículos médios ou pequenos ao estigma de carros econômicos, o que torna seus proprietários mal vistos socialmente. Carros são símbolos de status, mas carros econômicos teriam o efeito oposto. Outro problema está relacionado à existência de incertezas. A necessidade de substituição das baterias poderia inviabilizar o carro elétrico, visto que são dispendiosas e correspondem a grande parte do custo dos veículos. Além disso, sua durabilidade está abaixo do esperado para um veículo convencional, e a substituição das baterias é até um evento provável durante a vida útil dos veículos. Aliás, os autores não mencionam, mas esta tende a se reduzir quando se utiliza os smart grids. Todavia, os smart grids podem gerar receitas que custeiam a substituição das baterias.

Outro problema é a frustração dos consumidores com o desempenho substancialmente pior dos híbridos mais econômicos. Agrava isto o fato de que boa parte da economia de combustível gerada por esses veículos depende da maneira como eles são dirigidos, o que pode requerer uma reeducação cultural e na maneira dos motoristas conduzirem os PHEVs. Naturalmente, outra barreira são as preferências de grupos de consumidores por veículos de alto desempenho, o que dificultaria a penetração no mercado pelos PHEVs.

Por outro lado, há consumidores que desejam PHEVs em função de sua consciência ambiental e/ou sua oposição a guerras - supostamente motivadas pelas disputas acerca do petróleo.

Uma limitação técnica que pode decepcionar os consumidores é a variação da economia dos veículos híbridos, em função de mudanças de temperatura etc. Isto talvez comprometa a economia e atrapalhe a percepção pública dos veículos híbridos.

A falta de familiaridade dos consumidores com a tecnologia também pode atrapalhar, visto que as pessoas tendem a confiar investimentos substanciais a marcas e tecnologias de qualidade comprovada, o que pode impedi-los de experimentar as novas.

As empresas de petróleo poderiam se constituir em um forte opositor à adoção desses veículos. Como a demanda por combustíveis tenderia a cair, isso justificaria seus lobbies e campanhas públicas contra os PHEVs. Além destes perdedores óbvios, haveria as próprias indústrias consolidadas, que teriam de arcar com custos de alterar sua base produtiva e toda a rede de reparos e assistência dos veículos elétricos, que teriam menor tendência a necessitar de manutenção, de acordo com os autores.

Sovacool e Hirsch (2009) citam as barreiras como transponíveis, mas descartam a necessidade de apoio público, em especial no que tange ao abatimento do valor inicial de aquisição. Mas as vantagens dos veículos superariam essas barreiras e custos.

Van den Bulk e Hein (2009) busca comparar os custos de carros elétricos e a hidrogênio e confrontá-los com os carros a combustão, incluindo custos de aquisição, manutenção, depreciação e de combustível/energia nos Países Baixos. Após desenvolver cenários para distâncias percorridas anualmente, preço de energia e tempo de retenção de um veículo, são calculados os custos entre os anos de 2020 e 2030. Seu estudo concluiu que os carros elétricos apresentariam menores custos desde 2008, o que deve perdurar, mesmo sem contar seus benefícios ambientais e de diminuição da dependência em relação ao petróleo.

Perujo, Thiel e Nemry (2011) fazem uma análise dos custos e benefícios de veículos elétricos em contextos urbanos na Europa, considerando também as barreiras técnico-econômicas a sua adoção. Eles veem um impacto positivo na adoção de veículos elétricos em termos de redução de emissões de $\mathrm{CO}_{2}$ e de poluentes nocivos à saúde em grandes centros, sobretudo em função da maior eficiência 
energética dos motores elétricos. Eles listam, contudo, diversas barreiras à entrada dos elétricos no mercado, como os altos custos de aquisição, o custo total de manutenção, as dificuldades com a recarga, a percepção de segurança e a familiaridade com a tecnologia, entre outros fatores.

Apesar disso, uma das principais limitações é a financeira. Segundo suas estimativas, o tempo de payback de um EV seria de vinte anos, em 2010, oito anos, em 2020 e seis, em 2030, a partir de quando cai para cinco. São períodos muito longos, que dificultam a adoção desses veículos, o que sugere, para os autores, a necessidade de benefícios fiscais. Concluem o estudo ao considerar os EVs mais eficientes em termos de produção de gases, principalmente $\mathrm{CO}_{2}$, levando em conta a matriz energética local. Os PHEVs seriam uma boa opção intermediária até que os EVs possam atingir maiores fatias de mercado, quando as barreiras tecnológicas forem superadas, em função da curva de aprendizado. Até lá, sugerem ação de apoio do governo via subsídios, além de políticas públicas complementares, como regulações que favoreçam os veículos elétricos, bem como políticas de transporte coletivo sustentável, coibindo o transporte individual.

Van Essen e Kampman (2011) fazem uma avaliação dos carros elétricos do ponto de vista da produção de energia, bem como dos seus impactos sobre a composição dos meios de transporte, emissões etc. na União Europeia. Analisam custos, aspectos tecnológicos, a relação com o setor de produção de energia elétrica, análises econômicas do custo total de propriedade (TCO), modelos de negócios na venda, uso e distribuição de EVs etc. O estudo considera os veículos puramente elétricos, os PHEVs e os híbridos com range extender, isto é, que têm motores a combustão não para mover o veículo, mas exclusivamente para recarregar as baterias e estender a autonomia $\left(\mathrm{PHEV}_{\mathrm{RE}}\right)$. Os autores concluem que, ao contrário do que se espera, os PHEVs têm, em média, o mesmo peso aproximado dos veículos usualmente vendidos na Europa. Todavia, os PHEVs e EVs apresentam desempenho inferior aos veículos a combustão interna, o que pode limitar seu uso aos centros urbanos. Os autores estimam que o total de subsídios aos veículos com propulsão alternativa, entre 2008 e 2011, na UE, foi de $€ 22$ bilhões. Impostos e descontos, além de outras medidas regulatórias e administrativas, também são usados para promover os veículos de propulsão alternativa.

Ainda de acordo com Van Essen e Kampman (2011), a autonomia dos EVs e PHEVs é uma barreira considerável - além do desempenho, dos preços e da vida útil das baterias - à difusão dos EVs. Logo, é importante focar no desenvolvimento de baterias. Os autores fizeram entrevistas com especialistas, que concluíram que as expectativas acerca do desenvolvimento das baterias são de queda de $20 \%$ a $25 \%$ nos custos até 2016 e melhoria da energia específica de $70 \%$ a $75 \%$ entre 2020 a 2022. Há um potencial para triplicar a energia específica e reduzir o custo por KW em 70\%, em 2030. As pesquisas para o desenvolvimento desses veículos são lideradas pelos Estados Unidos, enquanto o Japão é líder quanto a tecnologias de baterias.

Van Essen e Kampman (2011) também afastam a possibilidade de falta de insumos importantes para as baterias, como lítio, por exemplo. De acordo com estimativas, mesmo que $100 \%$ dos carros sejam elétricos em 2040, ainda assim só $25 \%$ das reservas conhecidas de lítio teriam sido gastos com EVs.

São mencionadas questões de segurança, mas apenas as relativas a ausência de ruído por parte dos EVs, o que poderia provocar acidentes em cruzamentos, na medida em que as pessoas não percebem a aproximação dos carros.

Os autores também estimaram que, mesmo com a difusão dos PHEVs e EVs, a demanda por eletricidade seria atendida, em média, pelo sistema gerador. Todavia, em alguns centros mais isolados, a infraestrutura poderia não comportar o acréscimo de carga.

Há também problemas relativos a estações de recarga de veículos, que devem não apenas atender àqueles fora de suas residências, como também nelas, visto que na Europa - ao contrário dos Estados Unidos - muitos proprietários de veículos não possuem garagem. $\mathrm{O}$ investimento para a criação dessas estações seria muito pesado, e a sua baixa taxa de retorno também exigiria elevados incentivos fiscais e subsídios. Há, ainda, problemas quanto aos padrões de interface de recarga, que só serão unificados em 2017.

Outros problemas seriam relacionados ao custo total de propriedade dos automóveis (TCO), que seriam elevados nos EVs devido ao alto preço inicial e ao custo e à baixa longevidade das baterias, ainda que o preço da energia favoreça os elétricos. Suas estimativas indicam que o TCO dos PHEVs e HEVs, maiores que os dos veículos convencionais, só se aproximarão destes em 2030, com vantagem dos PHEVs sobre os HEVs.

[SYN]THESIS, Rio de Janeiro, vol.8, nº 2, 2015, p.45-63 
Managi (2012) estuda a viabilidade econômica de difundir no mercado veículos puramente elétricos ou a célula de combustível (hidrogênio), por meio de uma análise de custo-benefício privado. Ele sugere hipóteses acerca de progresso tecnológico, economias de escala e da disponibilidade de produção de energia elétrica por meios não poluentes ou renováveis. Seus resultados indicam que os veículos a célula de combustível somente se tornarão viáveis em 2110 , mesmo que seu custo caia ao valor dos veículos de combustão interna, enquanto os veículos puramente elétricos somente o serão em 2060, dependendo do aumento do preço da gasolina e dos subsídios ao abatimento de $\mathrm{CO}_{2}$. Além do custo, alguns dos problemas desses veículos são a baixa autonomia, além de outras dificuldades na adaptação dos mesmos ao estilo de vida dos proprietários/usuários.

Em suma, as análises focadas na viabilidade financeira não são muito animadoras, pois ressaltam não apenas os elevados custos e demorado período para obter o payback, mas também enfatizam as barreiras de comercialização desses veículos, ao chamar atenção à baixa autonomia das baterias, problemas relativos a sua infraestrutura de recarga, entre outros, notadamente a relação entre os preços de combustíveis e da energia. Sugere-se então a necessidade de subsídios a este tipo de veículo, o que, evidentemente, só pode ser considerado viável após uma valoração dos custos e benefícios sociais.

\section{ANÁLISES SOCIAIS}

As análises sociais podem tomar mais de um formato, considerando diversos tipos de situações: desde o impacto dos veículos elétricos ou híbridos sobre as respectivas redes de geração e distribuição de eletricidade, além das emissões totais de gases de estufa e de gases tóxicos. Algumas análises consideram as emissões totais durante a vida e fabricação do veículo, mas outras apenas computam as emissões well-to-grid ou well-to-wheel ou outros conceitos. Um método utilizado foi o uso de avaliações financeiras, que buscam precificar as externalidades e ajudar a determinar os montantes ideais de benefícios fiscais, por exemplo.

Todavia, esta seção se divide em dois tipos principais de análises: as que consideram a implantação das smart grids e as demais, que avaliam diferentes custos e benefícios, mas sem considerar os benefícios e custos relacionados às redes inteligentes de energia. Essas redes inteligentes usam as baterias dos veículos conectados à rede para suavizar a produção de energia, portanto, gerando potenciais economias substanciais relativas ao investimento e à manutenção da rede de energia elétrica, e podem ser fundamentais para a viabilidade dos veículos elétricos. Os resultados a seguir apresentados são extremamente sensíveis às emissões marginais de poluentes na geração de energia nas regiões específicas consideradas e, evidentemente, à hipótese de emprego das smart grids.

\subsection{IMPACTOS SOBRE AS REDES DE GERAÇÃO E DISTRIBUIÇÃO DE ENERGIA E OS BENEFíCIOS POTENCIAIS DAS SMART GRIDS}

Um dos possíveis custos sociais da adoção de veículos elétricos é o aumento da demanda de carga sobre o sistema elétrico e as redes de transmissão, que eventualmente necessitarão de investimentos para sua readequação, em adição ao crescimento natural da demanda por energia, oriundo da expansão das demandas tradicionais. Entretanto, o advento das redes inteligentes, que usam as baterias dos EVs conectados na rede para suprir picos de demanda de energia durante o dia e os carrega novamente à noite, pode significar que, quando consideradas as redes elétricas, os custos dos EVs e PHEVs podem ser, do ponto de vista social, menores que os custos que desconsideram essas externalidades.

Scott et al. (2007) apresenta uma análise econômica dos PHEVs, incluindo a avaliação do custo do ciclo de vida dos veículos (LCC - life-cycle cost) convencionais frente aos HEVs, incluindo nos cálculos também os impactos sobre a rede de produção de eletricidade. Os autores consideram custo de aquisição, taxa de desconto de mercado, vida útil esperada dos veículos, preços da gasolina e da eletricidade. São usados cenários alternativos quanto ao preço da gasolina e os investimentos na geração de energia. Um cenário mantém os parâmetros atuais, outro de curto prazo com aumento no custo da gasolina e outro de longo, com elevação no investimento em produção de eletricidade. A conclusão é que, mantidos os preços, os consumidores poderiam pagar um preço-prêmio acima dos preços dos veículos convencionais para comprar os PHEVs, mesmo quando se leva em conta os veículos convencionais mais populares e mais econômicos, e ainda assim obtendo retorno positivo. Os 
resultados da comparação com os HEVs dependem da evolução dos preços da gasolina e da energia elétrica. O impacto sobre a rede elétrica seria a de redução do custo médio da energia, sob a hipótese de existência de smart grids, pois uma grande adoção de PHEVs pode suavizar o consumo de energia, elevando a eficiência do uso do capital fixo.

Outros estudos abordam a viabilidade de substituir a frota por veículos elétricos, considerando a estrutura atual, sem os smart grids, o que mede a existência de barreiras de curto prazo à introdução desses veículos, do ponto de vista do fornecimento de energia elétrica. Kintner-Meyer, Schneider e Pratt (2007) fazem um estudo sobre a relação entre os PHEVs e a atual rede de produção e distribuição de eletricidade nos Estados Unidos, considerando não apenas as redes específicas, mas também as possibilidades de compra e venda de energia entre as regiões no país, que não tem um sistema tão interligado como o brasileiro. Concluem que a infraestrutura existente seria capaz de absorver uma substituição de $84 \%$ da frota de veículos - carros, picapes, SUVs - por veículos híbridos plug-in. Se fosse considerada toda a frota de veículos leves, a rede seria capaz de abastecer a substituição de $73 \%$ dos veículos. Contudo, isto poderia reduzir a confiabilidade do sistema, que trabalharia mais próximo da capacidade, a menos que se introduzam os smart grids, que poderiam melhorar a confiabilidade e reduzir a capacidade ociosa e os custos de operação da rede, o que pode ainda reduzir os preços da energia.

Também foram medidos outros benefícios sociais. Há impactos potencialmente significativos sobre as emissões ao substituir a frota por PHEVs. Gases de estufa seriam reduzidos, bem como algumas categorias de poluentes, mas haveria acréscimo na emissão de particulados e $\mathrm{SO}_{2}-$ especialmente nas térmicas dependentes de carvão e petróleo -, o que remete ao trade-off entre gases tóxicos e gases de estufa. Todavia, as emissões em áreas urbanas devem melhorar, em detrimento das áreas rurais, onde se localizam as termelétricas.

Uma mudança para os PHEVs reduziria o consumo de gasolina em 6,5 milhões de barris por dia, o equivalente a $52 \%$ das importações de petróleo dos Estados Unidos.

A esta altura, cabe notar a importância conferida ao uso de smart grids, bem como das tecnologias de geração de eletricidade e os combustíveis utilizados, para o sucesso dos PHEVs. De fato, diversos artigos quantificam os benefícios da utilização dos híbridos para regular a oferta e demanda de energia via V2G, como: Srivastava, Annabathina e Kamaladasan (2010), Markel, Kuss e Denholm (2009), Moorhouse e Laufenberg (2010), Van Essen e Kampman (2011) e White e Zhang (2011), entre outros. Esses artigos apresentam a tecnologia V2G e seus benefícios potenciais de reduzir a variância da demanda de energia elétrica sobre as geradoras, reduzindo o custo médio da energia e possibilitando aos proprietários de veículos elétricos o recebimento de receitas pela venda de energia acumulada nas baterias de seus veículos nos horários de pico - quando a energia é mais cara - e sua carga nos horários em que a eletricidade é mais barata. Além disso, entre outros benefícios, a existência de uma estrutura de armazenagem de eletricidade - propiciada pelas baterias dos EVs e PHEVs - permite que se aproveite melhor a energia gerada por fontes limpas, como a eólica, cuja produção é incerta e depende de fenômenos climáticos, e que portanto tem oferta dissociada dos momentos de maior demanda.

Sovacool e Hirsch (2009) discorrem acerca da ligação entre veículos híbridos - PHEVs - e sua integração com as redes de distribuição de energia elétrica (vehicle-to-grid, V2G). Ao mesmo tempo em que a energia elétrica daria aos carros a capacidade de serem não poluentes - ao menos por alguns quilômetros - e de elevar sua eficiência energética, diminuindo sua emissão de $\mathrm{CO}_{2}$, os veículos elétricos, simbioticamente, teriam a capacidade de melhorar a eficiência e reduzir os custos da geração e transmissão de energia, uma vez que os PHEVs contêm não apenas os motores a combustão, mas também baterias. Essas baterias, que usualmente seriam carregadas à noite, teriam a capacidade de elevar a oferta de energia elétrica na rede quando sua demanda - logo, seu preço - for mais alta. Assim, isto reduziria a necessidade das geradoras de energia ter grande capacidade ociosa nos períodos de baixa de demanda, visto que sua capacidade de geração deve ser limitada inferiormente pelo pico de utilização. Isto pode ocorrer, pois a maioria dos carros passa a maior parte do tempo em suas garagens, podendo, portanto, ser utilizados como baterias usadas para suavizar a demanda e a oferta de energia entre os picos e vales de demanda. Assim, os carros PHEV seriam carregados quando a demanda fosse baixa, logo a eletricidade mais barata. Quando a demanda fosse alta, os PHEVs retornariam eletricidade à rede, reduzindo custos das firmas produtoras e gerando receitas aos seus proprietários. Isto se soma à maior eficiência energética dos PHEVs para reduzir 
ainda mais seus custos de operação. O estudo de Sovacool e Hirsch (2009) mostra resultados que sugerem que os efeitos são substanciais em termos de potencial de oferta de energia. O artigo também discorre sobre os ganhos em termos de eficiência e redução das emissões de $\mathrm{CO}_{2}$ dos PHEVs.

Van Essen e Kampman (2011) fazem três cenários prospectivos que são analisados no modelo MELVIN, dependendo de algumas variáveis, como: custo de veículos e baterias, bem como sua longevidade; resposta dos consumidores às variações de preços dos PHEVs e EVs; disponibilidade de smart grids e pontos de recarga - inclusive para cargas durante o dia; política do governo e limitações da capacidade das baterias e de sua capacidade de produção. Nos três cenários - um otimista, um pessimista e outro mais "realista" -, obtém-se redução no consumo de combustíveis (petróleo e diesel), logo, também uma redução na emissão de $\mathrm{CO}_{2}, \mathrm{CO}$ e particulados, mas se elevam as emissões de $\mathrm{NO}_{\mathrm{x}}$, ainda que caiam os custos com a poluição do ar. Em todos os cenários, o aumento na demanda de eletricidade é relativamente pequeno, mas a maior parte da energia marginal vem de gás e carvão. $\mathrm{O}$ aumento da demanda por lítio e terras raras poderia ser atendido por reservas globais, mas a produção terá de ser expandida. $\mathrm{O}$ impacto fiscal tende a ser negativo sobre os orçamentos dos governos, inclusive porque os investimentos em estações de recarga prometem ser significativos. Até 2030 o impacto sobre as fontes primárias de energia deve ser pequeno, com variações na demanda por importações de petróleo incertas.

Para Van Essen e Kampman (2011), as sugestões de políticas públicas são: aumento das regulações sobre emissão de $\mathrm{CO}_{2}$; melhoria da contabilidade do consumo de eletricidade dos EVs; expansão da oferta de energia após 2030; elevação da taxação de energia suja; garantia da distribuição local de pontos de recarga e a adoção de padrões únicos de interfaces de recarga.

\subsection{DemAIS ANÁLISES DE CUSTO E BENEFíCIO SOCIAL}

De acordo com Wilkins (1997), as emissões dos veículos eram responsáveis por diversas doenças, mormente respiratórias, sem contar as de gases de estufa, que têm potencial para causar graves danos ambientais. Uma possível solução para tais emissões seria a adoção de veículos elétricos, que, diretamente, produzem pouca ou nenhuma poluição. Se grandes porcentagens da energia elétrica adviessem de fontes limpas, a emissão proveniente dos veículos seria irrelevante. Wilkins (1997) cita a Califórnia, que tinha apenas $20 \%$ da sua oferta de eletricidade associada a fontes sujas, como petróleo e carvão.

O problema é quando a geração de energia elétrica advém de fontes consideradas sujas, como carvão e petróleo. Além de $\mathrm{CO}_{2}$, emitem também gases tóxicos capazes de gerar doenças. Wilkins (1997) informa que onde apenas $21 \%$ da energia advêm de carvão e petróleo, como a região de Los Angeles, a substituição de veículos a combustão interna por elétricos reduziria em mais de 142 vezes as emissões de $\mathrm{CO}$, em $66 \%$ as de $\mathrm{CO}_{2}$, em $99 \%$ as de hidrocarbonetos e em $73 \%$ as de $\mathrm{NO}_{\mathrm{x}}$. Todavia, haveria um aumento de $72 \%$ nas emissões de $\mathrm{SO}_{2}$. Em regiões ainda mais concentradas em energia de carvão, como a Alemanha da época, manter-se-iam as emissões de $\mathrm{CO}_{2}$ e $\mathrm{NO}_{\mathrm{x}}$, desapareceriam as de $\mathrm{CO}$ e hidrocarbonetos, mas haveria um aumento de $900 \%$ no $\mathrm{SO}_{2}$. Se a produção de energia elétrica fosse $100 \%$ baseada na queima de carvão, $\mathrm{CO}$ e hidrocarbonetos continuariam com zero, mas as de $\mathrm{CO}_{2}$ subiriam $150 \%$, os $\mathrm{NO}_{\mathrm{x}} 230 \%$ e o $\mathrm{SO}_{2}$ em 25 vezes, quando comparadas às emissões dos automóveis convencionais, novamente sugerindo o trade-off entre a emissão de gases de estufa e gases diretamente ofensivos à saúde.

Wilkins (1997) lembra que nem toda a poluição dos carros elétricos advém da energia para sua utilização cotidiana. Deve também ser contabilizada a energia necessária para a produção e descarte das baterias - face ao que é gasto com veículos a combustão interna.

Uma vantagem, contudo, dos veículos elétricos é a maior facilidade relativa de controlar a poluição nas termelétricas, que são em muito menor número do que os carros, bem como a adoção de tecnologias mais limpas, por força de regulamentos, sobre as produtoras de energia. Além disso, os carros tendem a poluir mais à medida que envelhecem ao longo de sua vida útil, enquanto as termelétricas são mais sujeitas à fiscalização. Wilkins (1997) diz ser impossível afirmar se os veículos elétricos podem realmente ajudar a controlar a poluição no curto prazo, em função dos inúmeros fatores envolvidos. Todavia, em alguns centros urbanos muito poluídos e, em especial, onde os trajetos são curtos, pode haver um benefício ambiental local e mesmo global. Isto porque, além das limitações de autonomia das baterias, os veículos a combustão são mais poluentes e ineficientes 
quando operando sob temperaturas inferiores à ideal de funcionamento. Quando o trajeto diário se dá em distâncias insuficientes para atingir essas temperaturas, há um substancial aumento de consumo e poluição, que poderia ser evitado pelos veículos elétricos, ideais para curtos trajetos.

Carlsson e Stenman (2003) fazem uma análise de custo-benefício para o setor de transporte da Suécia, com perspectiva para 2010. Usando os preços sombra ambientais calculados em Sika (2000 apud Carlsson e Stenman, 2003), estimaram o valor presente líquido (VPL) social dos HEV em US\$ 4 mil negativos. Caso o governo mantenha instalações de recarga, este VPL social pode chegar a US\$ 10 mil negativos. Assim, Carlsson e Stenman (2003) avaliam que não vale a pena subsidiar veículos elétricos em grande escala, visto que eles não seriam socialmente lucrativos. Todavia, concluem que os híbridos, ao contrário dos puramente elétricos, podem ser socialmente vantajosos.

Stephan e Sullivan (2006) fazem uma análise da sensibilidade da emissão de $\mathrm{CO}_{2}$, nos Estados Unidos, à expansão da frota de PHEVs. Após análise cuidadosa da capacidade produtiva de eletricidade no país, bem como da produção marginal de $\mathrm{CO}_{2}$, obtêm-se resultados interessantes. Após comungarem da mesma conclusão de que o efeito líquido sob as emissões dos PHEVs depende crucialmente de que tipo de combustível é utilizado para produzir eletricidade, mas usando os valores marginais estimados de emissões de $\mathrm{CO}_{2}$ para os Estados Unidos - supondo que os PHEVs são carregados à noite, fora do horário de pico -, chegam à conclusão de que os PHEVs produzem 75\% do $\mathrm{CO}_{2}$ emitido por um HEV e $51 \%$ do emitido por um veículo convencional. Analisando, ainda, o benefício marginal de substituir veículos atuais por PHEVs ou alocar esses recursos para aposentar usinas geradoras de energia que utilizam tecnologia e combustíveis menos eficientes - notadamente carvão -, concluíram que se os PHEVs forem substituir os veículos a combustão interna, é preferível substituir os carros. Todavia, se os HEV forem substituir os veículos a combustão, é preferível aposentar as termelétricas mais ineficientes primeiro, se o objetivo é conter a emissão de $\mathrm{CO}_{2}$. Essas conclusões podem ser alteradas se forem considerados outros poluentes e se a maior preocupação for a poluição local.

Parks, Denholm e Martel (2007) fazem uma análise dos custos e benefícios dos PHEVs que são recarregados na área de atuação de uma empresa específica de produção e distribuição de energia, no estado do Colorado, nos Estados Unidos. A capacidade de geração de eletricidade no referido estado é, segundo a distribuição de fontes de energia: $45 \%$ de gás natural, $42 \%$ de carvão, $9 \%$ de hidrelétricas, $2 \%$ de petróleo e $2 \%$ de energias renováveis - incluindo vento. O consumo - que reflete a efetiva utilização da capacidade - segue o seguinte padrão: $71 \%$ de carvão, 24\% de gás natural, 3\% de energia hidrelétrica e $2 \%$ de renováveis.

O modelo utilizado considera os custos de geração e elevação da capacidade, bem como os benefícios de redução de emissões de $\mathrm{CO}_{2}, \mathrm{SO}_{2}$ e $\mathrm{NO}_{\mathrm{x}}$.

$\mathrm{O}$ consumo de energia dos PHEVs é calculado por meio do método Well-to-Wheel, usando a ferramenta ADVISOR, em função de hipóteses acerca das autonomias das baterias e de seus custos. Os efeitos líquidos são sumariados a seguir. Do ponto de vista da geração de energia, substituir 30\% da frota local por PHEVs - com baterias de autonomia de 20 milhas - elevaria a demanda de energia em 2,7\%. As estimativas apontam uma redução de emissões de $\mathrm{CO}_{2}$ de pouco mais de 6 toneladas por veículo por ano - veículos a combustão interna - para aproximadamente 3,5 toneladas por veículo por ano, no caso da adoção de PHEVs, na região. Até mesmo as emissões de $\mathrm{SO}_{2}$ apresentariam uma redução, em termos da média emitida por veículo, de aproximadamente 2,5 libras por ano para 1 libra a 2,2 libras, dependendo do padrão de recarga.

$\mathrm{O}$ aumento das emissões de $\mathrm{NO}_{\mathrm{x}}$ por conta da geração extra de energia seria praticamente equivalente à redução das emissões por veículos.

Samaras e Mesterling (2008) buscam quantificar as emissões de GHG de PHEVs versus HEVs; veículos convencionais e veículos movidos a etanol, usando dois cenários acerca da infraestrutura de produção de energia elétrica nos Estados Unidos - com alta e baixa emissão de carbono. Os autores lembram que o nível de emissões da rede elétrica, considerados todos os fatores, até as perdas de transmissão e de distribuição, é fundamental para determinar se os PHEVs são melhores ou piores, em termos de emissões, que os HEVs. O modelo utilizado é o descrito em Lave et al. (1995).

Os resultados indicam que, se o cenário for de manutenção das fontes de energia primárias na geração elétrica norte-americana, os PHEVs reduzem as emissões de GHG em até 32\% em relação aos veículos convencionais, pois parte das distâncias percorridas são alimentadas pela energia da rede, 
e entre $9 \%$ e $18 \%$ a menos que os HEVs. Se houver o cenário de baixas emissões na geração, os PHEVs podem reduzi-las de $51 \%$ a $63 \%$ versus os convencionais e de $30 \%$ a $47 \%$ versus os HEVs.

Mas em um cenário de alto consumo de carbono na geração elétrica, os HEVs podem ser de $9 \%$ a $18 \%$ menos poluentes que os PHEVs. Os carros a etanol reduziriam a poluição, mas há fortes limitações quanto a área plantada necessária para suprir a substituição do petróleo.

Samaras e Mesterling (2008) também citam a importância da longevidade das baterias, pois sua fabricação é muito intensiva em carbono e, caso seja necessário substituíllas durante a vida útil dos veículos, os resultados podem ser fortemente alterados. Os autores também citam a importância tanto da forma de dirigir os veículos quanto de carregá-los sobre o consumo, mencionando a necessidade do uso racional da rede.

Herynkova (2009) faz uma análise de custo-benefício da difusão dos veículos (puramente) elétricos na Dinamarca, com estimativas para o ano de 2020. Os benefícios ambientais são precificados em moeda local, após serem calculados com base nas emissões de $\mathrm{NO}_{\mathrm{x}}, \mathrm{CO}_{2}$, particulados e compostos orgânicos voláteis não metano (NMVOC), bem como a poluição sonora emitida pelos automóveis de combustão interna. ${ }^{7}$ Os custos são considerados principalmente em termos de renúncia fiscal, necessária para promover as vendas de veículos elétricos. A autora conclui que, por ampla margem, a renúncia fiscal é tão grande que os benefícios potenciais parecem "insignificantes": os benefícios sociais dos EVs, dependendo do cenário, variam entre $€ 17$ milhões e $€ 161,1$ milhões, enquanto os custos de renúncia fiscal variam entre $€ 225,6$ milhões e $€ 1$,86 bilhão. A autora afirma que, dada a estrutura de produção de eletricidade no país, os benefícios ambientais dos veículos são pequenos. Ela sugere uma combinação de políticas - como tributação ao uso de veículos e medidas regulatórias sobre a eficiência dos motores - e novas tecnologias biocombustíveis, hidrogênio e até a melhoria dos veículos a combustão - como solução mais viável para reduzir a emissão de gases de estufa e demais poluentes. Todavia, dado que seu modelo é estático, é possível que no longo prazo, políticas de estímulo aos EVs possam gerar ganhos de spillover e de tecnologia capazes de gerar benefícios líquidos, o que seu modelo não pode captar.

Moorhouse e Laufenberg (2010) fazem um estudo sobre a viabilidade dos carros elétricos na Colúmbia Britânica, no Canadá. Todavia, tal província tem uma característica diferente das da maioria dos estudos até aqui abordados: da eletricidade produzida no estado 93\% são limpas, visto que a maior parte da energia utilizada localmente é procedente de hidrelétricas, em semelhança com o Brasil, por exemplo.

Considerando que a energia marginal consumida pelos elétricos venha de fontes tão limpas quanto a energia ofertada atualmente, os "EVs são uma solução clara para as mudanças climáticas e preocupações com a qualidade do ar", na Colúmbia Britânica (MOORHOUSE; LAUFENBERG, 2010). As reduções projetadas de $\mathrm{NO}_{\mathrm{x}}, \mathrm{SO}_{2}, \mathrm{CO}$ e matéria particulada variam entre $10 \%$ e $99 \%$, mesmo considerando que a fabricação de carros com as baterias é muito mais carbono intensiva que no caso de carros movidos a combustão interna. Os autores também citam que a autonomia dos carros elétricos é suficiente para cobrir a grande maioria dos deslocamentos diários naquela província, visto que $95 \%$ deles são inferiores a $30 \mathrm{~km}$, devido ao fato de $73 \%$ da população viverem em áreas urbanas.

Esse estudo entende que carros híbridos também podem reduzir a poluição. De fato, carros elétricos reduzem as emissões de GHG em 80\%, híbridos plug-in em 55\% e os híbridos não plug-in em 30\% - apenas em função de serem mais eficientes que os carros a combustão, pois eles não têm interface com a rede elétrica, o que nesta província do Canadá contraria os objetivos de redução de poluição.

Axsen et al. (2011) estudam o impacto dos PHEVs sobre as emissões de GHG na atmosfera, utilizando dados de uma pesquisa com consumidores reais de PHEVs, acerca do seu padrão de uso dos veículos, incluindo aí os horários de carregamento etc. Eles confrontam esses dados com um modelo da rede elétrica da Califórnia, de modo a possibilitar a estimação well-to-wheel ${ }^{8}$ das emissões dos veículos, não considerando, portanto, as emissões com a manufatura e o seu descarte.

$\mathrm{O}$ estudo conclui que os PHEVs podem melhorar substancialmente a eficiência energética, reduzindo a emissão de $\mathrm{CHG}$ entre $19 \%$ e $74 \%$, dependendo das condições. Além disso, dada a base de geração de energia da Califórnia, veículos com baterias de menor autonomia (10 milhas) seriam mais benéficos em termos de redução de emissões, visto que, em alguns horários de recarga, uma milha percorrida com gasolina pode ser mais limpa que uma milha percorrida com eletricidade produzida nas usinas. Assim, carros movidos com baterias alimentadas pelo seu próprio motor a 
gasolina tendem a ser mais limpos. Todavia, os autores ressaltam que esses números médios podem mascarar o fato de que a substituição da frota por carros mais eficientes movidos a gasolina permite gerar efeitos parecidos, mas com custos menores que veículos híbridos.

Também são considerados, como já observado, os impactos dos veículos elétricos sobre as emissões de gases tóxicos (não necessariamente de estufa) e seus efeitos sobre a população.

Talvez o artigo mais pessimista quanto aos benefícios da adoção de veículos com propulsão alternativa seja o de Michalek et al. (2011). O estudo desses autores faz uma análise dos custos e benefícios dos veículos elétricos (EVs), híbridos (HEVs) e híbridos do tipo plug-in (PHEVs). São consideradas na análise as emissões de $\mathrm{CO}_{2}$ na produção das baterias, na geração de eletricidade, no refino e na produção de gasolina (well to pump), da política de defesa norte-americana - associada à segurança energética, logo, manutenção da disponibilidade de petróleo -, bem como da emissão de partículas e gases tóxicos e suas externalidades, entre outros fatores. Os resultados indicam que em função da matriz energética norte-americana, fortemente baseada em termelétricas, os EVs e os PHEVs com baterias grandes - que oferecem maior autonomia - tenderiam a ser mesmo prejudiciais às emissões de GHGs, dependendo das condições da evolução do sistema de geração de energia nos Estados Unidos. Nos cenários mais otimistas, contudo, esses veículos poderiam contribuir com a redução das emissões, tudo dependendo do $\mathrm{CO}_{2}$ e $\mathrm{SO}_{2}$ para fabricação de baterias e de produção de eletricidade. Os veículos tipo HEV - que não podem ser recarregados nas tomadas - e os PHEVs com baixa autonomia - limitam a utilização de energia produzida na rede - tenderiam a reduzir as emissões e os custos de energia para os proprietários de veículos.

Michalek et al. (2011) recomendam o corte de subsídios a veículos com baterias de longa autonomia, bem como subsídios ao aprimoramento da tecnologia de baterias - que reduzam seus custos - e de geração limpa de energia elétrica.

O artigo de Ji et al. (2012) faz um estudo acerca dos impactos da introdução de veículos elétricos na China no que diz respeito à emissão de $\mathrm{CO}_{2}$ e de poluentes causadores de doenças. São usadas informações não apenas das emissões dos veículos comuns - a gasolina e a diesel - mas também as emissões das geradoras de energia, que costumam ficar afastadas dos grandes centros. Em função do fato de a matriz energética chinesa concentrar $85 \%$ da geração de energia em combustíveis fósseis, dos quais $90 \%$ compostos por carvão mineral, os achados desencorajam a adoção de veículos elétricos. Não apenas as emissões de $\mathrm{CO}_{2}$ e de todos os demais poluentes se elevam, como também se transfere poluição dos centros ricos para as zonas rurais mais pobres. As emissões de particulados se elevam drasticamente, o que é amenizado apenas em função do fato de que, no campo menos densamente povoado, a fração respirada (intake fraction - iF) é menor. Assim, carros elétricos elevariam o número de mortes e de emissão de $\mathrm{CO}_{2}$ na China, em boa parte em função da ineficiência na geração de energia no país. Possivelmente, os resultados seriam diferentes em países com a matriz energética mais limpa.

\section{CONCLUSÃO}

Os achados da literatura sugerem que os carros elétricos, mesmo que superiores em termos de viabilidade econômica e eficiência energética aos movidos a hidrogênio, ainda enfrentam importantes barreiras que os impedem de substituir no curto e médio prazos os veículos convencionais a combustão. Uma solução alternativa que vem ganhando espaço são os veículos híbridos, em especial os do tipo plug-in, que podem obter energia tanto da gasolina quanto da rede elétrica. Ainda que mais caros e pesados que os HEVs e os veículos a combustão, podem combinar muitas das vantagens de cada tecnologia - baixas emissões dos elétricos com a grande autonomia e facilidade de reabastecimento dos veículos a combustão -, gerando veículos menos poluentes e economicamente viáveis, ao mesmo tempo em que superam diversas barreiras que tornam os veículos elétricos substitutos por demais imperfeitos em relação aos veículos tradicionais, aos olhos dos consumidores.

A tecnologia, contudo, não está livre de desafios, como o custo das baterias, sua vida útil e seus impactos sobre a rede elétrica, bem como o fato de sua viabilidade econômica e ambiental depender também da tecnologia e dos custos de geração de energia elétrica, bem como de seus preços relativos, em especial os da gasolina. Fica patente a necessidade de melhorias na tecnologia das baterias, pesadas, caras, de relativamente baixa densidade energética - quando comparadas à gasolina - e de durabilidade e segurança incertas. 
Dessa forma, a viabilidade dos PHEVs está intimamente ligada à análise caso a caso da geração de eletricidade regional para verificar a relação custo benefício destes veículos, em termos financeiros e ambientais. Importa não apenas verificar quão limpa e sustentável é a matriz energética. Mais que isso, é importante também verificar quão limpa é a geração incremental de energia, sob pena de trocar um tipo de poluição por outro, a custo financeiro elevado. Por isso, é relevante avaliar, caso a caso, se os custos de implementar melhorias na eficiência e no nível de emissões das geradoras de energia são maiores ou menores que promover a substituição dos veículos a combustão por híbridos e/ou elétricos, pois, provavelmente, este resultado irá variar de um contexto para outro.

Ainda assim, os híbridos, indiscutivelmente, apresentam o potencial de formar a próxima geração de veículos, que fará a transição entre os atuais modelos petróleo-dependentes para os modelos puramente elétricos, assim que as tecnologias de baterias e a de geração de energia permitirem.

Até que isso ocorra, uma das melhorias mais extraordinárias que os PHEVs podem ajudar a viabilizar é a tecnologia $\mathrm{V} 2 \mathrm{G}$, que permite que os veículos sejam carregados na rede elétrica nos momentos de baixo consumo de eletricidade - notadamente à noite - e que sua energia acumulada possa devolver carga à rede para auxiliar a geração nos momentos de pico de demanda. Isto não apenas pode reduzir a poluição gerada pelas térmicas, mas também diminuir o custo fixo do setor elétrico, gerando receitas de venda de energia aos proprietários dos PHEVs, as quais podem ser usadas para a substituição de baterias quando e se essas chegarem ao fim de sua vida útil, se o fizerem antes dos veículos. Outro ponto positivo dos PHEVs é que eles podem continuar a aproveitar as inovações e melhorias de eficiência que certamente ocorrerão nos motores a combustão, visto que eles contam com um. Logo, os PHEVs podem se beneficiar de inovações oriundas de ambas as tecnologias: e a velha, focada na melhoria da eficiência energética dos motores a combustão, que continuam seu processo evolutivo, e a nova, focada nas baterias, motores elétricos e mecanismos de recuperação de energia.

Essas tecnologias, incluindo os smart grids, podem posteriormente ser aproveitadas pelos EVs em um prazo mais longo, quando estiverem mais maduras. Mas sua integração com a rede elétrica exige, contudo, planejamento, investimento e coordenação, o que representa um grande desafio às autoridades, às montadoras e às empresas de produção de energia, criando um cenário em que todos os agentes da economia saem ganhando, o que garante a sua viabilidade no longo prazo.

Para o caso brasileiro, cabe ressaltar que a adoção ou não de veículos elétricos e/ou híbridos deve considerar os seguintes fatores: uma análise de custo benefício acerca da introdução de veículos elétricos, tendo em vista o razoável grau de penetração no mercado de biocombustíveis, notadamente o etanol. Assim, é primordial comparar as emissões dos veículos a etanol com gasolina, elétricos (well-to-wheel) e híbridos, mas sem esquecer da possibilidade da liberação da comercialização dos veículos a diesel, que certamente são mais eficientes que os a gasolina e podem representar uma forma custo-eficiente de reduzir as emissões. Além disso, é importante analisar quão limpa é a estrutura de produção marginal de eletricidade - independentemente de quão limpa é, em média, a matriz energética atual -, o que envolve a necessidade de quantificar os impactos de um eventual acréscimo de demanda por energia sobre a capacidade produtiva brasileira, visto que ela passou por recentes períodos de estresse com risco de interrupção generalizada do fornecimento de energia, bem como as formas de gerar energia limpa incremental, também em função de o Brasil estar se aproximando do esgotamento do potencial de expansão hidrelétrica. Cabe lembrar que a energia hidrelétrica - predominante no Brasil - é uma das poucas energias (relativamente) limpas que permitem a estocagem e a regulação da produção, por meio do represamento da água. Se o manejo é bem feito, isto potencialmente reduz os impactos positivos das smart grids, ainda que não os anule. $\mathrm{O}$ Brasil, em função do baixo aproveitamento de redes ferroviária e hidroviária, também tem alto potencial de economia de emissões de carbono - e de custo - ao transferir parte do transporte de carga para hidrovias, cabotagem e hidrovias, o que pode envolver investimentos públicos e a suspensão do subsídio ao diesel - tornando as alternativas ao transporte rodoviário relativamente ainda mais baratas -, que impede a sua adoção por veículos individuais de pequeno porte. Seria interessante avaliar esses fatores antes de propor políticas custosas aos consumidores que, de acordo com o que se viu na literatura, podem ou não ser vantajosas econômica ou socialmente, dependendo das características e idiossincrasias locais.

No que concerne à literatura, foram percebidas algumas lacunas. A primeira delas é que faltam avaliações objetivas dos valores dos subsídios frequentemente propostos, mas raramente qualificados 
para: $i)$ garantir a atratividade dos veículos elétricos ou híbridos aos olhos dos consumidores; e ii) assegurar que os subsídios levem à obtenção de um ótimo social, o que envolve, naturalmente, um dispêndio fiscal responsável e adequado às finanças públicas de cada ente geográfico envolvido. A segunda é a ausência quase total das estimativas técnicas dos carros elétricos/híbridos de devolução de energia à rede em momentos de consumo de pico, o que, naturalmente, envolve a estimativa tanto da capacidade das baterias quanto da disponibilidade de veículos para tal operação, o que abrange não apenas a quantidade de veículos produzidos, mas também estimativas acerca de seu modo de uso por parte do consumidor, visto que é preciso que o veículo esteja parado e conectado à rede para devolver a energia à rede. Além disso, é preciso estimar os custos envolvidos em capacitar a rede para captar, de forma tão capilar, e aproveitar essa energia.

Talvez tão importante quanto estudar a viabilidade de transportes individuais elétricos, seja o estudo de alternativas, custos e benefícios de expandir, modernizar o implantar de novas soluções no transporte público elétrico, o que é uma extensão lógica natural dessa linha de pesquisa.

Finalmente, a literatura acaba por expor mais resultados qualitativos que quantitativos, o que tem relação com a dificuldade de estimar as inúmeras variáveis em ação, mas que dificultam uma análise por frequentemente omitir parte dos custos e dos benefícios. Assim, é preciso estender as pesquisas no sentido de considerar todo o espectro de custos, benefícios e disposições a pagar, de modo a prover uma avaliação isenta e mais precisa dos custos e benefícios possíveis com as novas tecnologias. Em especial, é imperativo ampliar o número, o escopo e a profundidade das análises de ciclo da vida dos veículos elétricos, especialmente à luz da dificuldade em dispor de baterias no ambiente, visto que são compostos complexos de materiais tóxicos e perigosos. É nesse sentido que deve caminhar a literatura sobre o tema.

\section{REFERÊNCIAS BIBLIOGRÁFICAS}

AXSEN, J. et al. Plug-in hybrid vehicle GHG impacts in California: integrating consumer-informed recharge profiles with an electricity-dispatch model. Energy Policy, n. 39, p. 1617-29, 2011.

BOND Jr., V. Fisker Karma hybrids burn during superstorm Sandy. Autoweek, Oct. 2012. Disponível em: <http://goo.gl/a6hole>. Acesso em: 5 May 2015.

BRASIL. Ministério da Ciência, Tecnologia e Inovação. Estimativas anuais das emissões de gases de efeito estufa no Brasil. Brasília, 2013. Disponível em: <http://goo.gl/cT3zrp>. Acesso em: 5 maio 2015.

CARLSSON, F; STENMAN, O. J. Cost and benefits of electric vehicles a 2010 perspective. Journal of Transport Economics and Policy, n. 37, p. 1-28, 2003.

COOPER, C.; MATSUDA, K. GS Yuasa Crisis Deepens With Mitsubishi Car-Battery Fire. Bloomberg, Mar. 2013. Disponível em: <http://goo.gl/jmVlJT>. Acesso em: 5 maio 2015.

HERYNKOVA, H. Impact analysis of difusion of electric vehicles in Denmark. Dissertação (Mestrado) - Lund University, Lund, Suécia, 2009.

INTERGOVERNMENTAL PANEL ON CLIMATE CHANGE (IPCC). The physical science basis. New York: Cambridge University Press, 2013. Disponível em: <http://goo.gl/CGg9mX>. Acesso em: 5 maio 2015.

JENSEN, C. Chevy volt fire prompts federal investigation intolithium-ion batteries. The New York Times, nov. 2012. Disponível em: <http://goo.gl/9zMcDT>. Acesso em: 5 maio 2015.

JI, S. et al. Electric vehicles in China: emissions and health impacts. Environmental Science and Technology, v. 46, p. 20182024, 2012.

KINTNER-MEYER, M.; SCHNEIDER, K.; PRATT, R. Impact assessment of plug-in hybrids on electric utilities and power grids. Pacific Northwest National Laboratory, 2007. Disponível em: <https://goo.gl/dbw1q5>. Acesso em: 5 maio 2015.

MANAGI, S. Analysis of alternative fuel vehicles by disagreggated cost benefit. RIETI, May 2012. (Discussion Paper Series 12-E035). Disponível em: <http://goo.gl/dKMgzQ>. Acesso em: 5 maio 2015.

MICHALEK, J. et al. Valuation of plug-in vehicle life-cycle air emissions and oil displacement benefits. PNAS, v. 108, n. 40, p. 16554-16558, Oct. 2011.

MOORHOUSE, J.; LAUFENBERG, K. Electric vehicles powering the future. The Pembina Institute Backgrounder. Sept. 2010. 21p.

MOTTA, R.; HARGRAVE, J.; LUEDEMANN, G. As metas do acordo de Copenhague e as decisões de Cancun. In: Motta, R.; HARGRAVE, J.; LUEDEMANN, G.; GUTIERREZ, M. (Eds.). Mudança do clima no Brasil: aspectos econômicos, sociais e regulatórios. Brasília: Ipea, 2011.

PARKS, K.; DENHOLM, P.; MARTEL, T. Costs and emissions associated with plug-in hybrid electric vehicle charging in the xcel energy Colorado service territory. May 2007. (Technical Report for the National Renewable Energy Laboratory, NREL/TP-640-41410).

PERUJO, A; THIEL, C.; NEMRY, F. Electric vehicles in urban context: environmental benefits and techno-economic barriers. In: SOYL, S. (Eds.). Electric vehicles: the benefits and barriers, 2011. 
ROMM, J. The car and fuel of the future. Energy Policy, n. 34, p. 2609-2614, 2006.

SAMARAS, C.; MESTERLING, K. Life cycle assessment of greenhouse gas emissions from plug-in hybrid vehicles: implications for policy. Environmental Science and Technology, v. 42, n. 9, p. 3170-3176, Apr. 2008.

SCOTT, M. et al. Impact assessment of plug-in hybrid vehicles on electric utilities and regional U. S. Power grids Part 2: economic assessment. Pacific Northwest National Laboratory, 2007. Disponível em: <http://goo.gl/CVWHwf >. Acesso em: 5 maio 2015.

SIMPSON, A. Cost-benefit analysis of plug-in hybrid electric vehicle technology. Conference Paper NREL/CP-540-40485. In: THE $22^{\text {ND }}$ INTERNATIONAL BATTERY, HYBRID AND FUEL CELL ELECTRIC VEHICLE SYMPOSIUM AND EXIBITION, Yokohama, Japan. Nov. 2006.

SOVACOOL, B.; HIRSH, R. Beyond batteries: an examination of the benefits and barriers to plug-in-hybrid electric vehicles (PHEVs) and a vehicle-to-grid (V2G) transition. Energy Policy, n. 37, p. 1095-1103. 2009.

SRIVASTAVA, A.; ANNABATHINA B.; KAMALADASAN, S. The challenges and policy options for integrating plug-in hybrid vehicles into the electric grid. The Electricity Journal, v. 23, n. 3, p. 83-91, 2010.

STEPHAN, C.; SULLIVAN, J. Environmental and energy implications of plug-in hybrid vehicles. Environmental Science \& Technology, v. 42, n. 4, p. 1185-1190. 2006.

SWAN, T. Volkswagen Jetta Hybrid vs. Jetta GLI vs. Jetta TDI vs. Jetta 2.5. Car and Driver, Apr. 2013. Disponível em: $<$ http://goo.gl/abHdm7>. Acesso em: 5 maio 2015.

VAN DEN BULK, J.; HEIN, L. G. A cost-benefit analysis of combustion cars, electric cars and hydrogen cars in the Netherlands: The development of the costs and benefits of cars powered by gasoline, electricity and hydrogen in the Netherlands in the period 2008-2030. Wageningen University, 2009. Disponível em: <http://goo.gl/1rtVJr>. Acesso em: 5 maio 2015.

VAN ESSEN, H.; KAMPMAN, B. Impact of electric vehicles. Delft: Jan. 2011. 25p. (Summary Report 11.4058.26).

ZITO, P.; SILVA, S. Potential demand and cost-benefit analysis of electric cars. European Transport, n. 27, p. 1-14, 2004.

WHITE, C.; ZHANG, K. Using vehicle-to-grid technology for frequency regulation and peak-load reduction. Journal of Power Sources, n. 196, p. 3972-3980, 2011.

WILKINS, J. Will electric vehicles really reduce pollution? 1997. (Mimeo.). Disponível em: <http://goo.gl/hVyKAJ>. Acesso em: 5 maio 2015.

\section{Bibliografia COMPLEMENTAR}

CONSTANTINE, S.; MESTERLING, K. Life cycle assessment of grenhouse gas emissions from plug-in hybrid vehicles: implications for policy. Environmental Science and Technology, v. 42, n. 9, p. 3170-3176, Apr. 2008.

DUBEUX, C. Mudança do clima. Rio de Janeiro: Universidade do Estado do Rio de Janeiro, 8 jul. 2013. (Mimeo.). Disponível em: <http://goo.gl/kS2As7>. Acesso em: 5 maio 2015.

GREEN, J.; WELCH, D.; KEANE, A. G. GM volt fire after crash said to prompt lithium-battery probe. Bloomberg, Nov. 2011. Disponível em: <http://goo.gl/QBG7X4>. Acesso em: 5 maio 2015.

MARKEL, T.; KUSS, M.; DENHOLM, P. Communication and control of electric vehicles supporting renewables. National Renewable Energy Laboratory Conference, Aug. 2009. (Paper, NREL/CP-540-46224).

ROMM, J.; FRANK, A. Hybrid vehicles gain traction. Scientific American, v. 294, n. 4, Apr. 2006.

\section{NOTAS EXPLICATIVAS}

${ }^{1}$ Dados referentes apenas ao $\mathrm{CO}_{2}$, não incluindo outros gases de estufa medidos em carbono equivalente.

${ }^{2}$ Esse acordo não é um tratado, logo, as metas lá traçadas não são obrigatórias ou vinculantes. A expectativa é de que a Conferência das Nações Unidas para Mudanças Climáticas vá produzir um acordo mais abrangente e vinculante no primeiro trimestre de 2015, tendo em vista que a última conferência das partes (COP 19) chegou à data de encerramento antes que houvesse um acordo.

${ }^{3}$ Há três tipos básicos de veículos elétricos. O primeiro deles são os veículos puramente elétricos, os EV's (Electric Vehicles), que são movidos por motores elétricos, que dependem de baterias, usualmente carregadas por meio da rede elétrica. O segundo e terceiro tipos são variantes do que chamamos híbridos. Os híbridos (HEV) envolvem a combinação de motores a combustão com motores elétricos que usam baterias. Esses, por sua vez, se dividem em duas categorias. Os HEVs (simples), que têm suas baterias carregadas somente pelo motor a combustão do próprio veículo e os PHEVs (Plug-in Hybrid Electric Vehicles) que, além de ter suas baterias carregadas pelo motor a combustão, também têm a opção de carregá-las junto à rede elétrica.

${ }^{4}$ Os plug-in hybrid vehicles (PHEVs) ou veículos híbridos podem ser carregados pela energia elétrica da tomada, em adição à energia gerada pelo motor a combustão do próprio veículo.

${ }^{5}$ Algumas dessas tecnologias que, contudo, hoje estão sendo aplicadas nos veículos convencionais, especialmente a direção eletricamente assistida e os mecanismos start-stop, que desligam automaticamente os veículos quando parados em sinais de trânsito ou em engarrafamentos.

${ }^{6}$ A chamada smart grid consiste na adoção de mecanismos inteligentes de utilização da rede de produção e distribuição de eletricidade, que utiliza as baterias dos veículos PHEVs conectados à rede para suavizar a demanda e a oferta de eletricidade entre os momentos de pico e de menor consumo de eletricidade. Durante os períodos de baixa demanda, a rede carregaria as baterias, mas nos momentos de pico as baterias forneceriam energia à rede, gerando, inclusive, renda aos proprietários desses veículos, otimizando o uso do capital na geração de eletricidade e reduzindo seu custo fixo. 
${ }^{7}$ De acordo com Moorhouse e Laufenberg (2010), o monóxido de carbono (CO) pode reduzir a capacidade do sangue de levar oxigênio ao cérebro, coração e outros tecidos, podendo resultar desde deficiências respiratórias até morte por asfixia. Os óxidos de nitrogênio (NOx) podem irritar os pulmões e reduzir sua resistência a infecções respiratórias. Sob algumas condições climáticas, os NOx podem reagir com outros compostos químicos e provocar a formação de ozônio no nível do solo, bem como chuva ácida e material particulado secundário. O material particulado - conhecido como PM2.5 - poder ser respirado, e contém substâncias nocivas à saúde, podendo levar à morte prematura, agravar a asma, gerar sintomas respiratórios agudos e bronquite. Além disso, ele pode diminuir a visibilidade atmosférica. Os óxidos de enxofre, SOx, podem causar dificuldades respiratórias, agravamento de doenças cardiorrespiratórias preexistentes e levar à morte. Também pode interagir com outros compostos e provocar a chuva ácida. Adicionalmente, Moorhouse e Laufenberg (2010) citam outros compostos orgânicos voláteis, que podem ser cancerígenos e reagir com o NOx, gerando ozônio ao nível do solo.

${ }^{8}$ Trata-se da quantificação das emissões desde a prospecção de petróleo, carvão e gás, passando pela geração de energia até seu uso na locomoção veicular. 